\title{
Relative Susceptibility of Four Coleopteran Stored-product Insects to Diatomaceous Earth SilicoSec $®$
}

\author{
Baba Gana Jugudum Kabir and Muhammad Lawan \\ Department of Crop Protection, Faculty of Agriculture, University of Maiduguri, Maiduguri P.M.B. 1069, Borno State, Nigeria
}

\begin{abstract}
Laboratory bioassays were conducted to evaluate the insecticidal effect of diatomaceous earth (DE), SilicoSec against Callosobruchus maculatus (F.), Rhyzopertha dominica (F.), Sitophilus zeamais (Motschulsky), and Tribolium castaneum (Herbst) in cowpea, maize and wheat, at $25-32{ }^{\circ} \mathrm{C}$ and $54-68 \%$ relative humidity (r.h.). SilicoSec was applied at rates: 0 (untreated control) 250 , 500,750 and $1,000 \mathrm{mg} / \mathrm{kg}$ of commodity. Adult mortality was measured after 3 to 14 days of exposure. Progeny production was assessed after 40 or 56 days. The tested species varied in sensitivity to SilicoSec, with $S$. zeamais being most susceptible, but no significant differences in mortality levels observed between $R$. dominica, C. maculatus or T. castaneum after three days of exposure. After 5 days of exposure, all $C$. maculates adults died on cowpea treated at $1,000 \mathrm{mg} / \mathrm{kg}$. Similarly, after 14 days of exposure all adults of the other species died on grains treated at $1,000 \mathrm{mg} / \mathrm{kg}$, and were ranked in decreasing order of susceptibility $S$. zeamais $>T$. castaneum $>R$. dominica. SilicoSec treatments suppressed progeny production (30 to 100\%) in all the tested species. The implications of these findings to DE-based control strategy are discussed.
\end{abstract}

Key words: Diatomaceous earth, insect species, susceptibility, control strategy.

\section{Introduction}

The use of fumigants and conventional neurotoxic insecticides as grain protectants are unsuccessful in controlling store product pests because of environmental problems such as pollution and mammalian toxicity [1]. Resistance of pests to residual insecticides and the demand for residue-free food have led researchers to evaluation of new-reduced risk insecticides to control stored product pest $[2,3]$.

One of the most well-studied and most promising alternatives to traditional neurotoxic grain protectants is the use of DE [4-8]. Diatomaceous earths are naturally occurring siliceous sedimentary mineral compound formed from the fossils of tiny phytoplanktons (diatoms) which absorb the epicuticular lipids of the insect cuticle, causing death

Corresponding author: Baba Gana Jugudum Kabir, Dr., Ph.D., research field: stored products entomology. through desiccation [9]. They are known to protect commodities against stored-product pests in two ways. First, DE particles are picked up by the insect as they walk through the commodity. The body of adult stored-product insects is made up of an exoskeleton covered with waterproofing waxes and lipids. The wax layer on the insect's epicuticle is damaged and insects lose water through the cuticle $[10,11]$. In addition, another mode of action of DE is its ability to repel insects [12].

While several DE formulations have been evaluated and shown to be effective, chiefly as grain protectants, and many of them are now commercially available in many parts of the world [13], many researchers underline the fact that DE efficacy can be affected by several biotic or abiotic factors e.g. temperature [2, 14-16], moisture content or relative humidity [15, 17-19], and type of grain commodity [4, 20, 21]. Laboratory experiments have also revealed significant effect of insect species [15], insect strain [22, 23], 
stage [19, 24]. Apart from the importance of the strain used, other authors underlined the importance of the age of the test insect [25].

Previous studies document that $R$. dominica and $T$. castaneum were among the most tolerant species to DE. Sitophilus spp. were reported to be moderately tolerant to DE. However, there is dearth of published information regarding the tolerance of C. maculatus in relation to other well studied species. This study was therefore undertaken to evaluate the relative response of four coleopteran stored product species to SilicoSec and determine the relative susceptibility of $C$. maculatus.

\section{Materials and Methods}

\subsection{Insects}

The insects tested were C. maculatus, $R$. dominica, $S$. zeamais and T. castaneum. These were collected from gain stores in Maiduguri and subsequently cultured in the laboratory on cowpea, wheat, maize and wheat flour, respectively, for several generations in the laboratory.

\subsection{Grains}

Three grain types were used in the experiments: cowpea, maize and wheat. The grains were cleaned and disinfested in an electric oven set at $55{ }^{\circ} \mathrm{C}$ for three days, then allowed to equilibrate under ambient conditions for 10 days prior to the experiments.

\subsection{DE Formulation}

The DE formulation used was SilicoSec (Biofa $\mathrm{GmbH}$, Munsingen, Germany). SilicoSec is a relatively new $\mathrm{DE}$ formulation of freshwater origin containing $92 \% \mathrm{SiO}_{2}, 3 \% \mathrm{Al}_{2} \mathrm{O}_{3}, 1 \% \mathrm{Fe}_{2} \mathrm{O}_{3}$, and $1 \%$ $\mathrm{Na}_{2} \mathrm{O}$ with average particle size between 8 and $12 \mu \mathrm{M}$ [23]. The SilicoSec sample was obtained from Diatom Research and Consulting Inc., Canada. The DE was stored in the laboratory at ambient conditions in airtight polyethylene sachet until commencement of experiments.

\subsection{Experimental Procedure}

Four concentrations of DE were used $(250,500$, 750 and $1,000 \mathrm{mg} / \mathrm{kg}$ ). Glass bottles (250 mL capacity) were filled with $50 \mathrm{~g}$ of cowpea, wheat or maize. The appropriate amount was weight and placed into each bobble. Untreated grains served as control. Bottles were sealed and shaken manually for $3 \mathrm{~min}$ to distribute DE in whole grain mass. Twenty $1-48 \mathrm{~h}$ old adults $C$. maculates were placed in each bottle containing cowpea, S. zeamais - on maize, while $R$. dominica and T. castaneum - on wheat. These three species were aged 7-21 days. Each species was treated separately and each treatment was repeated three times. The bottles were kept under ambient laboratory conditions. Total numbers of living and dead adults were recorded after 3 and 5 days for C. maculatus, and after 3, 7 and 14 days in the cases of $R$. dominica, $S$. zeamais and $T$. castaneum. This was done very carefully to avoid loss of eggs and larvae that are external to the grain kernels. The temperature and relative humidity were measured by using Omson's hygrometer.

After the 5 and $14 \mathrm{~d}$ mortality count all adults (dead and alive) were removed from the bottles, and the bottles were left at the same conditions for an additional period of 35 days in the case of $C$. maculatus and 42 days in the cases of the three other species. The number of emerged adults of each species was then counted.

\subsection{Data Analysis}

Where the mortality exceeded $5 \%$, counts were corrected using Abbott's [26] formula. The data on mortality and progeny were arcsine and square root transformed, respectively prior to analysis. All data were analyzed using the GLM Procedure of Statistix 8.0 , with insect mortality and number of progeny as the response variables and DE dose rate and exposure interval as the main effects. In all cases, means were separated by using the Tukey-Kramer (HSD) test, at $P \leq 0.05$. 


\section{Results}

The mean adult mortalities of $C$. maculatus, $S$. zeamais, $R$. dominica and $T$. castaneum after three days of exposure (Fig. 1) illustrates their relative susceptibility to SilicoSec. Within this exposure period $>50 \%$ of all exposed adults died. S. zeamais appeared to be the most susceptible species, while differences in mortality levels among the three other species were not significant.

Adult mortality among in the beetle species $S$. zeamais, $R$. dominica and T. castaneum was significantly affected by both DE and exposure period (Fig. 2). In all cases mortality was significantly lower in the untreated control than in treated grains in which case it increased with increase in dose rate and exposure period. After the three days exposure mortality level of $S$. zeamais was higher than of the other species, exceeding $95 \%$ on maize treated at $1,000 \mathrm{mg} / \mathrm{kg}$ of SilicoSec. With $R$. dominica and $T$. castaneum exposed to the same DE dose rate on wheat, mortality levels did not exceed 75\% (Fig. 2a). After seven days of exposure to DE treated commodities mortality in all the three species increased exceeded 50\% when SilicoSec was used at $250 \mathrm{mg} / \mathrm{kg}$. Within this exposure period wide differences in mortality levels were noted between species, especially when the DE was applied at 500 and $750 \mathrm{mg} / \mathrm{kg}$. However, at 1,000 $\mathrm{mg} / \mathrm{kg}$ such differences were not noted between $R$. dominica and T. castaneum (Fig. 2b).

Increase in exposure period further increased mortality levels. Thus 14 days of exposure to grains treated with the lowest dose rate $(250 \mathrm{mg} / \mathrm{kg})$ of SilicoSec resulted in death of $>80 \%$ of exposed adults of the three insect species. In the case of $S$. zeamais all adults died on maize treated at $\geq 500 \mathrm{mg} / \mathrm{kg}$ of SilicoSec. In a similar manner, complete mortality of $T$. castaneum and $R$. dominica adults was recorded at $\geq 750 \mathrm{mg} / \mathrm{kg}$ and $1,000 \mathrm{mg} / \mathrm{kg}$, respectively (Fig. 2c). The same trend as observed for the preceding species was noted for $C$. maculatus. That more beetle died with increase in DE dose rate and exposure period. After 3 days of exposure adult mortality increased from $29.9 \pm 3.35$ at $250 \mathrm{mg} / \mathrm{kg}$ to $70.8 \%$ at 1,000 $\mathrm{mg} / \mathrm{kg}$, while after five days of exposure, the corresponding values were $63.2 \%$ and $100 \%$, respectively (Fig. 3).

However, when the susceptibility of $S$. zeamais, $R$. dominica and T. castaneum were compared after 14 days of exposure, a different outcome was obtained. In this case, $R$. dominica was the most tolerant, followed by $T$. castaneum and $S$. oryzae remained the most susceptible (Fig. 4).

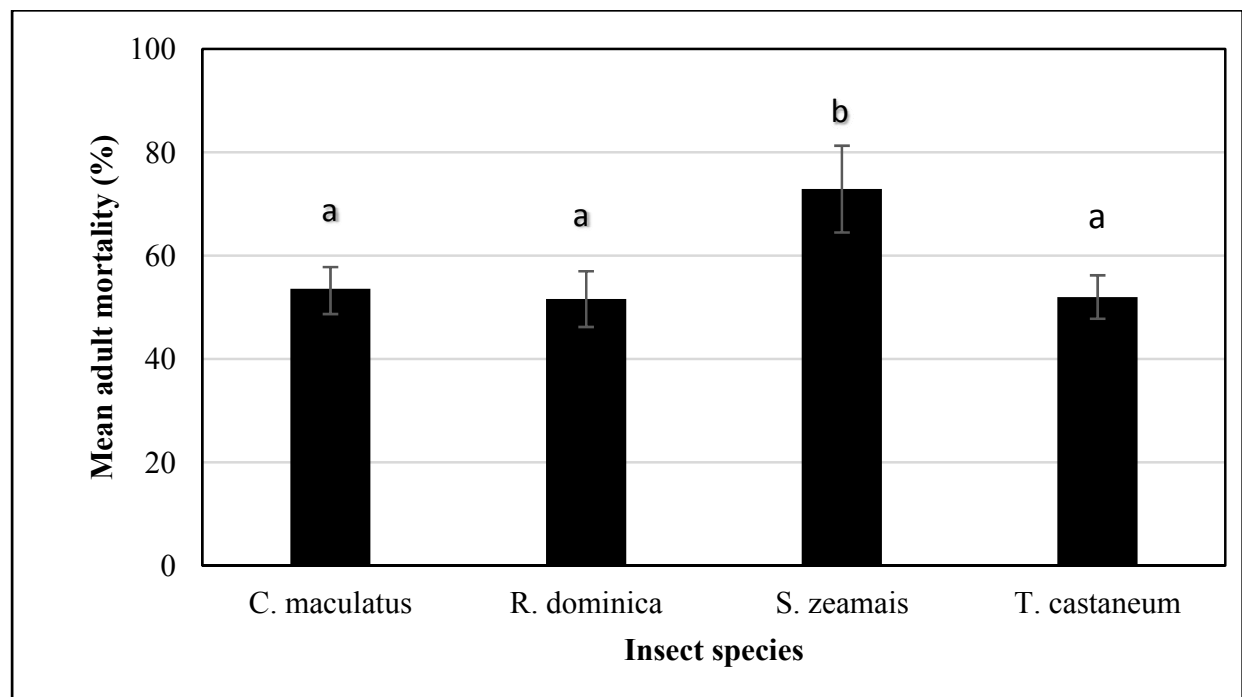

Fig. 1 Mean adult mortality of four insect species after three days of exposure to SilicoSec treated grains; means accompanied by different letters are significantly different (Tukey-Kramer HSD test, $P>0.05$ ). 


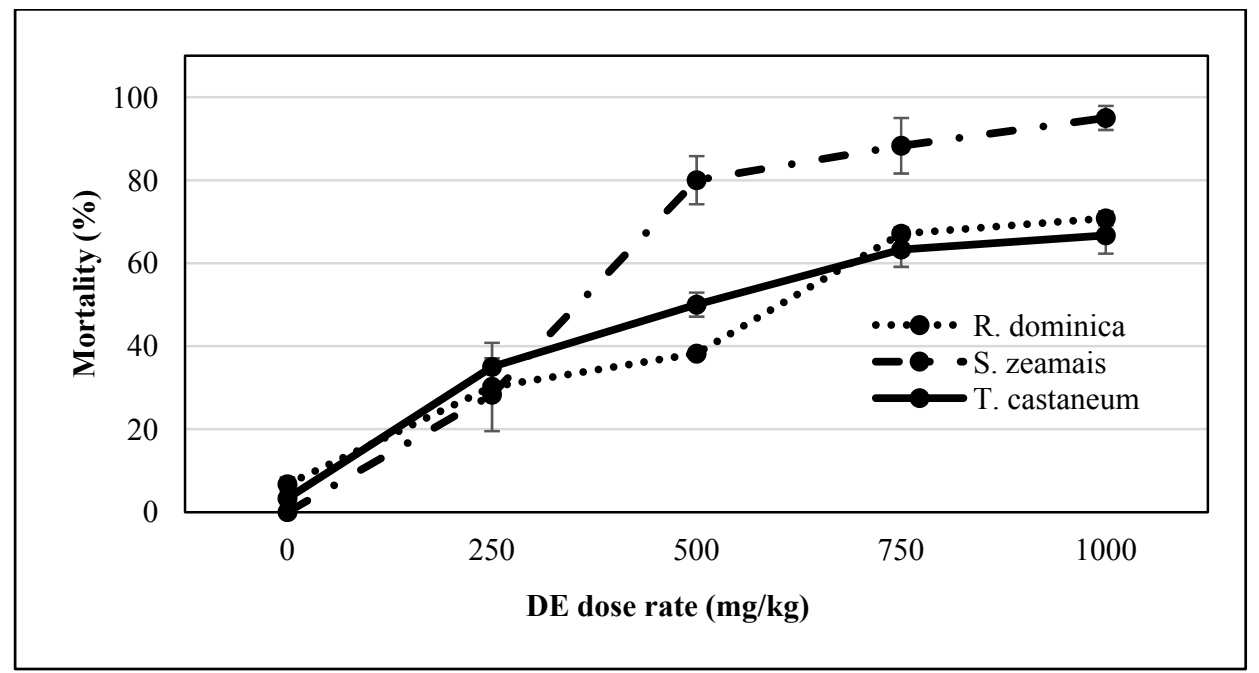

(a)

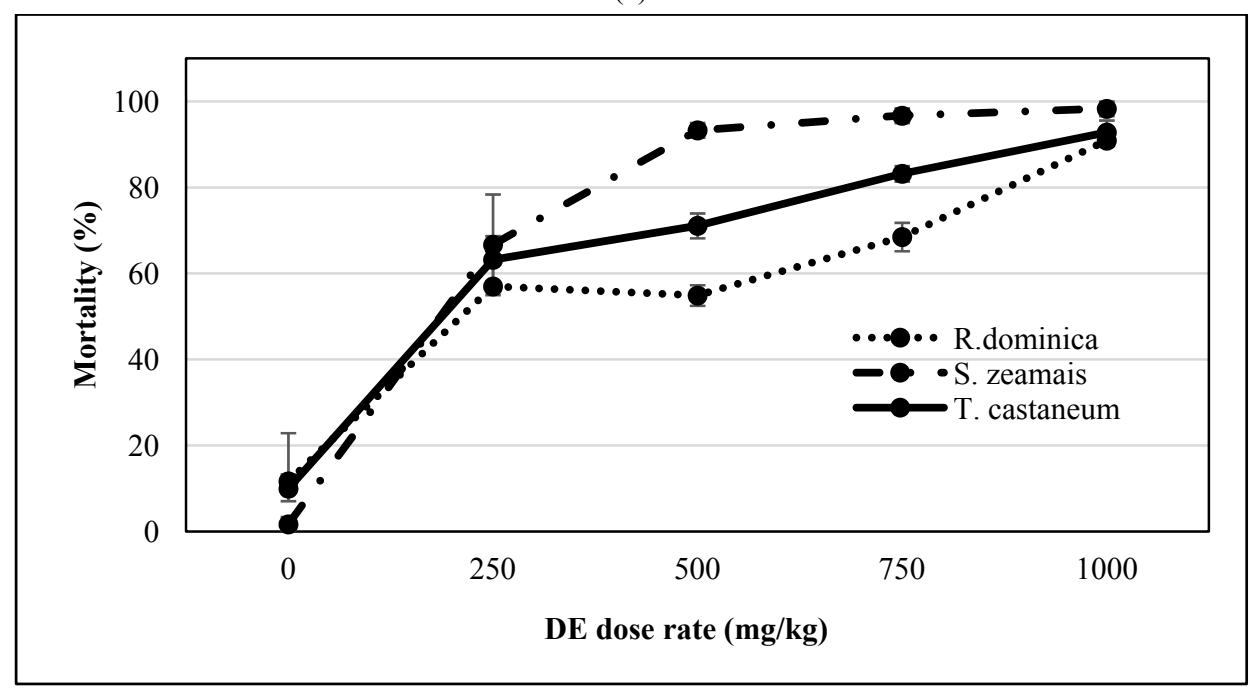

(b)

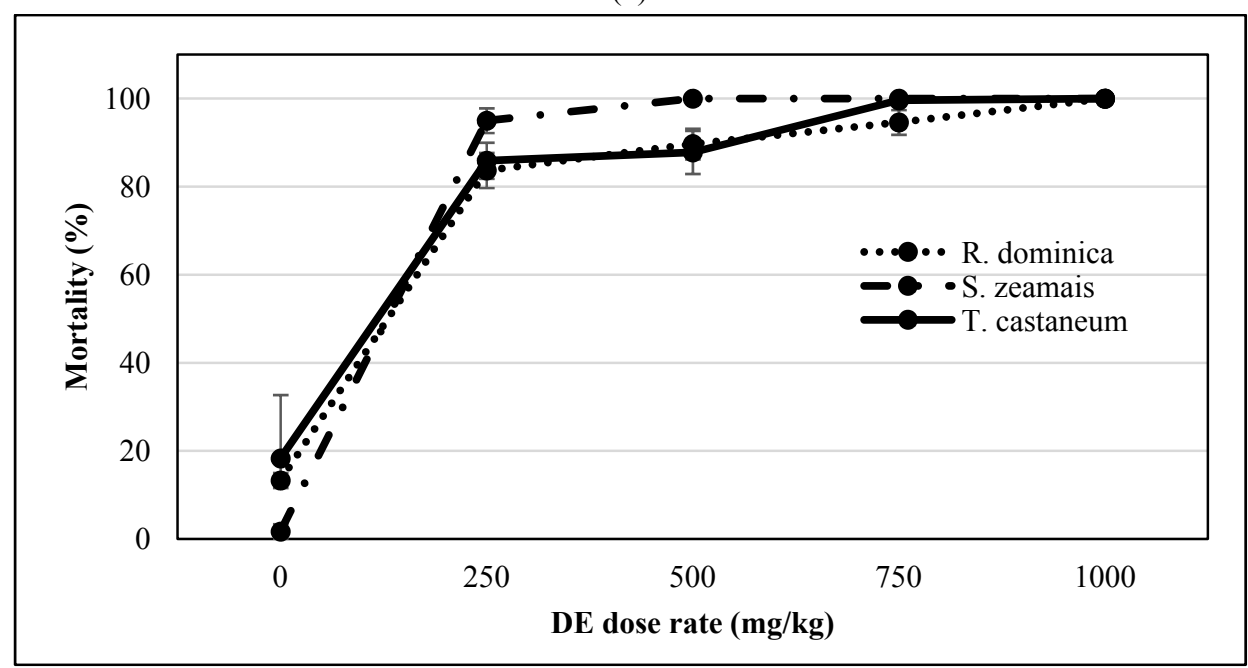

(c)

Fig. 2 Percentage mortality of $R$. dominica, S. zeamais and T. castaneum adults after 3 (A), 7 (B) and 14 (C) days of exposure to different dose rates of SilicoSec. 


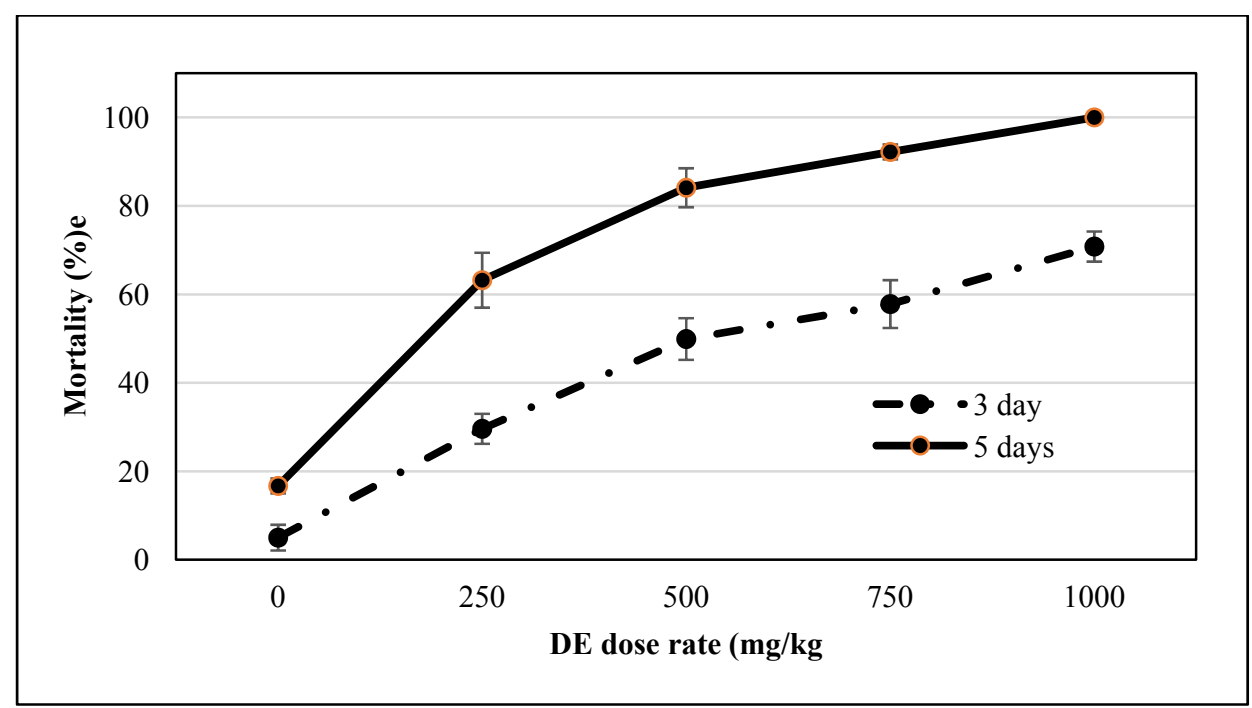

Fig. 3 Mortality of $C$. maculatus adults after three and five days of exposure to different dose rates of SilicoSec.

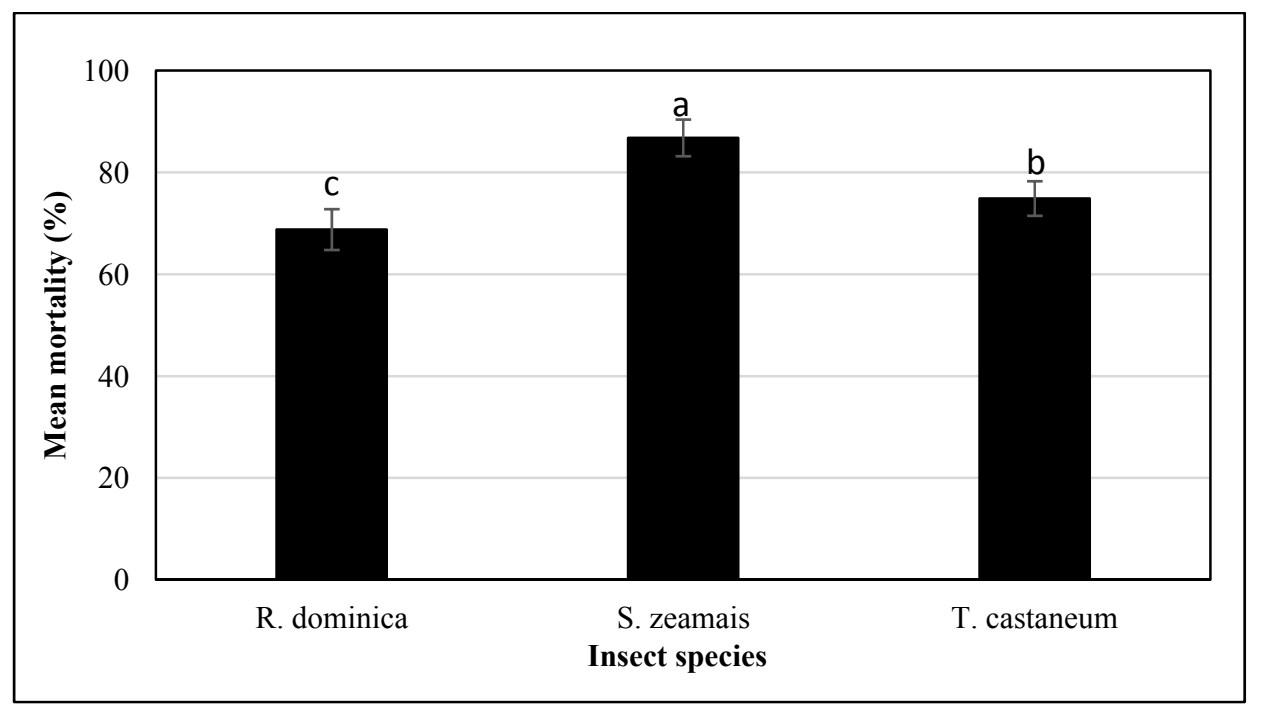

Fig. 4 Mean cumulative mortality of three insect species after 14 days of exposure to DE SilicoSec; means accompanied by different letters are significantly different (Tukey-Kramer HSD test, $P>0.05$ ).

Progeny production in all the four species tested was significantly affected by DE treatment. Very high number of $C$. maculatus adults emerged in the untreated cowpea than in treated ones. This was followed by $S$. zeamais and $R$. dominica and the least by $T$. castaneum (Table 1 and 2). With all the tested species, however, the number of progeny in the untreated control was significantly higher than in the treated grains. Generally, progeny production in the treated grains was very low and did not exceed 8 individuals in grains treated at $250 \mathrm{~g} / \mathrm{kg}$ of SilicoSec. With $T$. castaneum no adult progeny emerged in wheat treated at $750 \mathrm{mg} / \mathrm{kg}$ or more. Moreover, substantial proportions of emerged adults of $S$. zeamais, $R$. dominica and $T$. castaneum were dead at the time of progeny counts. Progeny suppression relative to the untreated increased with increase in $\mathrm{DE}$ dose rate. This was particularly very high on grains treated with $750 \mathrm{mg} / \mathrm{kg}$ of SilicoSec or more. With the exception of $S$. zeamais on maize treated at $250 \mathrm{mg}$ / $\mathrm{kg}$ more than $50 \%$ of potential $\mathrm{F} 1$ progeny were suppressed (Tables 1 and 2).

\section{Discussion}

This study demonstrated that the DE formulation, SilicoSec was effective against $C$. maculatus, $S$. 
zeamais, R. dominica and T. castaneum on stored cowpea, maize and wheat. The initial 3 days' adult mortality showed that $S$. zeamais was the most susceptible species, while the responses of the three other insect species to SilicoSec were similar. However, after 14 days of exposure, $R$. dominica was the most tolerant, followed by $T$. castaneum and $S$. oryzae remained the most susceptible. It is a known fact that stored product beetles vary widely in their susceptibility to DE [27]. Sitophilus spp. are usually ranked midway in susceptibility between the small mobile insects such as Cryptolestes spp. or Oryzaephilus spp. and the lesser grain borer $R$. dominica and Tribolium spp. which are more tolerant to inert dusts $[11,27,28]$. Our results with regards to $S$. zeamais are well in agreement these reports. Moreover, Korunic and Fields [29] found that $S$. zeamais was the most susceptible to DE among the Sitophilus spp.

The most interesting finding in this study is the relative susceptibility of $C$. maculatus, which was not widely reported in previous literatures. Based on the 3

Table 1 Effect of different doses of SilicoSec on progeny production of three stored product insect species.

\begin{tabular}{|c|c|c|c|c|}
\hline Insect species & $\mathrm{DE}$ dose rate $(\mathrm{mg} / \mathrm{kg})$ & $\begin{array}{l}\text { No. of progeny (mean } \pm \\
\text { SE) }\end{array}$ & $\begin{array}{l}\text { Percentage of dead } \\
\text { progeny }\end{array}$ & Progeny suppression (\%) \\
\hline \multirow[t]{7}{*}{ R. dominica } & 0 & $43.7 \pm 4.7 \mathrm{a}$ & $8.6 \pm 1.2 b$ & - \\
\hline & 250 & $21.3 \pm 10.4 \mathrm{ab}$ & $64.5 \pm 12.3 \mathrm{ab}$ & 51.3 \\
\hline & 500 & $3.0 \pm 1.7 b$ & $55.6 \pm 19.4 \mathrm{ab}$ & 93.2 \\
\hline & 750 & $3.3 \pm 1.9 b$ & $95.2 \pm 4.8 \mathrm{a}$ & 92.5 \\
\hline & 1,000 & $4.0 \pm 1.5 b$ & $100 \pm 0.0 \mathrm{a}$ & 90.8 \\
\hline & $F$ & 11.6 & 6.5 & \\
\hline & $P$ & 0.0009 & 0.0076 & \\
\hline \multirow[t]{7}{*}{ S. zeamais } & 0 & $43.3 \pm 4.8 \mathrm{a}$ & $10.7 \pm 2.2 \mathrm{c}$ & - \\
\hline & 250 & $30.0 \pm 10.0 \mathrm{ab}$ & $43.1 \pm 5.3 b$ & 30.7 \\
\hline & 500 & $7.7 \pm 2.4 b c$ & $83.5 \pm 8.4 \mathrm{a}$ & 82.2 \\
\hline & 750 & $4.0 \pm 2.0 \mathrm{c}$ & $95.8 \pm 4.2 \mathrm{a}$ & 90.8 \\
\hline & 1,000 & $5.7 \pm 2.6 c$ & $100 \pm 0.0 \mathrm{a}$ & 86.8 \\
\hline & $F$ & 12.3 & 61.3 & \\
\hline & $P$ & 0.0007 & $<0.0001$ & \\
\hline \multirow[t]{7}{*}{ T. castaneum } & 0 & $24.0 \pm 7.0 \mathrm{a}$ & $10.7 \pm 1.7 b$ & - \\
\hline & 250 & $8.7 \pm 2.2 \mathrm{a}$ & $95.2 \pm 4.8 \mathrm{a}$ & 63.8 \\
\hline & 500 & $1.3 \pm 0.7 b$ & $83.3 \pm 16.7 \mathrm{a}$ & 95.8 \\
\hline & 750 & $0.0 \pm 0.0 \mathrm{~b}$ & $100 \pm 0.0 \mathrm{a}$ & 100 \\
\hline & 1,000 & $0.0 \pm 0.0 \mathrm{~b}$ & $100 \pm 0.0 \mathrm{a}$ & 100 \\
\hline & $F$ & 25.5 & 24.0 & \\
\hline & $P$ & $<0.0001$ & $<0.0001$ & \\
\hline
\end{tabular}

Means within a species and a column followed by the same letter are not significantly different (Tukey-Kramer HSD, $P>0.05$ ).

Table 2 Effect of different doses of SilicoSec on progeny production of $C$. maculates.

\begin{tabular}{lll}
\hline DE dose rate $(\mathrm{mg} / \mathrm{kg})$ & No. of progeny $($ mean $\pm \mathrm{SE})$ & Progeny suppression $(\%)$ \\
\hline 0 & $152.0 \pm 12.5 \mathrm{a}$ & - \\
250 & $13.30 .9 \mathrm{~b}$ & 91.3 \\
500 & $6.0 \pm 2.1 \mathrm{bc}$ & 96.1 \\
750 & $2.7+0.9 \mathrm{~cd}$ & 98.2 \\
1,000 & $0.7 \pm 0.7 \mathrm{~d}$ & 99.5 \\
\hline
\end{tabular}

Means within a column followed by the same letter are not significantly different (Tukey-Kramer HSD test, $P>0.05$ ). 
day mortality $C$. maculatus, appeared to share the same level of tolerance to DE, in particular to SilicoSec with $R$. dominica and $T$. castaneum. Tolerance of $C$. maculates to DE may be attributed to the presence of hairs on the cuticle. As hairy insects tend to be less susceptible than insects with fewer hairs because hairs prevent dust particles from coming in contact with the cuticle [11]. In addition other factors such as size, rate of feeding (which does not apply to $C$. maculatus, as the adults do not feed) cuticular waxes, adhesion of DE to cuticle, absorbance of water from the hind gut or tolerance to low internal water are involved in tolerance to DE. However the exact mechanism of tolerance in $C$. maculatus is not yet established.

Our results showed that $R$. dominica was more tolerant than $T$. castaneum after 14 days of exposure. Results from previous studies comparing these species were somewhat inconsistent. For example, Kostyukovsky et al. [12] showed that $T$. castaneum was more tolerant than $R$. dominica to Detia Degesch Diatomaceous Earth (DDDE). Similarly, Baldassari et al. [30] reported higher mortality of $R$. dominica compared to $T$. castaneum on wheat treated with Protector $^{\circledR}$. However, Fields and Korunic [15] showed same level of tolerance to DEs by these two species. Yet, Kabir et al. [31] worked with same strains of insects used in the present study and found that more adults of $T$. castaneum than that of $R$. dominica died following exposure to wheat and maize grains treated with raw DE.

It is not known whether the results obtained in this study would hold true under different conditions. Perhaps different results may be obtained if the DE were to be tested on grains other than wheat or maize because DE efficacy is known to vary among grain types $[4,5,16,32]$. The susceptibility of a given species to DE might be influenced by the insect strain [33]. For instance, Rigaux et al. [22] and Vayias et al. [23] found considerable variations in susceptibility levels $T$. castaneum and $T$. confusum populations respectively, obtained from different locations. This may explain the lower tolerance of $T$. castaneum compared to $R$. dominica to SilicoSec noted in the present study. Kavallieratos et al. [33] noted that knowledge of the exact species to be controlled may help the correct design of a DE-based control strategy. Our results suggest that in addition to species, information on the susceptibility of the strain concerned may help improve a given strategy.

SilicoSec treatment reduced progeny production in all the four species tested. With the exception of $T$. castaneum complete progeny suppression was not achieved. Progeny suppression was attributed to the fact that DE limits insects mating activity by physically hindering movement [34]. Few adult progeny emerged because the females might have laid eggs before being killed by the DE. Mewis and Reichmuth [35] working with $S$. granarius exposed to DE treated wheat made similar observations. They reported that the adults died within a few days, which was time enough to produce progeny. In this regard the speed of parental mortality is important, so that insect die fast with very few eggs laid in treated commodity. Complete suppression of $T$. castaneum progeny in wheat treated SilicoSec at 750 or 1,000 $\mathrm{mg} / \mathrm{kg}$ may be explained by the fact this species is an external feeder, with all life stages found external to the grain kernels. Thus, the larvae were exposed to DE particles. Kostyukovsky et al. [12] reported that larvae of $T$. castaneum are very susceptible to DE. Tribolium castaneum is a secondary pest which thrives well on processed cereals or damaged grains. Also the larvae of $T$. castaneum need grain dust and damaged kernels to feed on, but these were substantially removed in the process of clearing. This partly explains the lower number of $T$. castaneum adults in the untreated control relative to other species tested. It is also shown that adult stage of insects are more tolerant to DE than larval stages [24, 36]. Although the immature stages of $C$. maculatus, $S$. zeamais and to some extent of $R$. dominica were not directly affected by DE particles, 
high mortalities were recorded as they emerged as adults as evidenced by the increasing percentages of dead progeny in treated grains. This also supports early reports that presence of $\mathrm{DE}$ in commodity gradually eliminates population of insects $[28,33]$.

In conclusion, the present study demonstrated that SilicoSec applied at $1,000 \mathrm{mg} / \mathrm{kg}$ could control $C$. maculatus, $S$. zeamais, $R$. dominica and $T$. castaneum in stored cowpea, maize and wheat. Initial mortality showed that $C$. maculatus adults exhibited same level of tolerance to SilicoSec as $R$. dominica and $T$. castaneum, whereas $S$. zeamais was the most susceptible species. Based on the results of the present study and available literature, knowledge of species composition and strain sensitivity to DE are important in devising a DE-based integrated management of stored product insects.

\section{Acknowledgments}

We most sincerely thank Dr. Zlatko Korunic (Diatom Research and Consulting Inc., Canada) for providing the DE quantities for experimentation and his useful comments on the draft manuscript before journal submission. We also thank Mr. Joshua B. Ndirmbula and Mr. Isaac C. Moses for their technical assistance.

\section{References}

[1] Chintzoglou, G., Athanassiou, C. G., and Arthur, F. H. 2008. "Insecticidal Effect of Spinosad Dust, in Combination with Diatomaceous Earth against Two Stored-grain Beetle Species.” Journal of Stored Products Research 44: 347-53.

[2] Aldryhim, Y. N. 1993. "Combination of Classes of Wheat and Environmental Factors Affecting the Efficacy of Amorphous Silicadust, Dryacide, against Rhyzopertha dominica (F.)." Journal of Stored Products Research 29: 271-5.

[3] Subramanyam, Bh., and Hagstrum, D. W. 1996. Resistance Measurement and Management. In Bh. Subramanyam and D.W. Hagstrum (eds.), Integrated Management of Insects in Stored Products (pp. 33-389). Marcel Dekker, New York.

[4] Athanassiou, C. G., Kavallieratos, N. G., Tsaganou, F. C., Vayias, B. J., Dimizas, C. B., and Buchelos, C. Th. 2003.
"Effect of Grain Type on the Insecticidal Efficacy of SilicoSec against Sitophilus oryzae (L.) (Coleoptera: Curculionidae)." Crop Protection 22: 1141-7.

[5] Athanassiou, C. G., Kavallieratos, N. G., Economou, L. P., Dimizas, C. B., and Vayias, B. J. 2005. "Persistence and Efficacy of Three Diatomaceous Earth Formulations against Sitophilus oryzae (Coleoptera: Curculionidae) on Wheat and Barley." Journal of Economic Entomology 98 : 1404-12.

[6] Athanassiou, C. G., and Korunic, Z. 2007. "Evaluation of Two New Diatomaceous Earth Formulations, Enhanced with Abamectin and Bitter Bark Omycin, against Four Stored-grain Beetle Species." Journal of Stored Products Research 43: 468-73.

[7] El-Wakeil, N. E., and Saleh, S. A. 2009. "Effects of Neem and Diatomaceous Earth against Myzus persicae and Associated Predators in Addition to Indirect Effects on Artichoke Growth and Yield Parameters." Archives of Phytopathology and Plant Protection 42: 1132-43.

[8] Vayias, V. J., and Stephou, V. K. 2009. "Factors Affecting the Insecticidal Efficacy of an Enhanced Diatomaceous Earth Formulation against Stored Product Insect Species." Journal of Stored Products Research 45: 226-31.

[9] Sabbour, M. M., Abd-El-Aziz1, S. E., and Sherief, M. A. 2012. "Efficacy of Three Entomopathogenic Fungi Alone or in Combination with Diatomaceous Earth Modifications for the Control of Three Pyralid Moths in Stored Grains." Journal of Plant Protection Research 52: 359-63.

[10] Ebeling, W. 1971. "Sorptive Dusts for Pest Control." Annual Review of Entomology 16: 123-58.

[11] Subramanyam, Bh., and Roesli, R. 2000. Inert Dusts. In Bh. Subramanyam and D.W. Hagstrum (eds.), Alternatives to pesticides in stored-product IPM. (pp. 321-80). Kluwer Academic Publishers, Dordrecht, The Netherlands.

[12] Kostyukovsky, M., Trostanetsky, A., Menasherov, M., Yasinov, G., and Hazan, T. 2010. "Laboratory Evaluation of Diatomaceous Earth against Main Stored Product Insects." In: Carvalho, M. O., Fields, P. G., Adler, C. S., Arthur, F. A., Athanassiou, C. G., Campbell, J. F., Fleurat-Lessard, F., Flinn, P. W., Hodges, R. J., Isikber, A. A., Navarro, S., Noyes, R. T., Riudavetes, J., Sinha, K. K., Thorpe, G. R., Timlick, B. H., Trematerra, P., White, N. D. G. (Eds), Proceedings of the 10th International Working Conference on Stored Product Protection, June 27 to 2 July, 2010. Estoril, Portugal. pp. 701-4.

[13] Athanassiou, C. G., Kavallieratos, N. G., Vayias, B. J., and Panoussakis, E. C. 2008. "Influence of Grain Type on the Susceptibility of Different Sitophilus oryzae (L.) Populations, Obtained from Different Rearing Media, to 
Three Diatomaceous Earth Formulations." Journal of Stored Products Research 44: 279-84.

[14] Aldryhim, Y. N. 1990. "Efficacy of the Amorphous Silica Dust, Dry Acide, against Tribolium confusum Du Val and Sitophilus granarius (L.) (Coleoptera: Tenebrionidae and Curculionidae)." Journal of Stored Products Research 26: 207-10.

[15] Fields, P., and Korunic, Z. 2000. "The Effect of Grain Moisture Content and Temperature on the Efficacy of Diatomaceous Earths from Different Geographical Locations against Stored-product Beetles." Journal of Stored Products Research 36: 1-13.

[16] Kavallieratos, N. G., Athanassiou, C. G., Paschalidou, F. G., Andris, N. S., and Tomanovic, Z. 2005. "Influence of Grain Type on the Insecticidal Efficacy of Two Diatomaceous Earth Formulations against Rhyzopertha dominica (F) (Coleoptera: Bostrychidae)." Pest Management Science 61: 660-6.

[17] Arthur, F. H. 2000. "Toxicity of Diatomaceous Earth to Red Flour Beetles and Confused Flour Beetles (Coleoptera: Tenebrionidae): Effects of Temperature and Relative Humidity." Journal of Economic Entomology 93: 526-32.

[18] Arthur, F. H. 2002. "Survival of Sitophilus oryzae (L.) on Wheat Treated with Diatomaceous Earth: Impact of Biological and Environmental Parameters on Product Efficacy." Journal of Stored Products Research 38: 305-13.

[19] Vayias, B. J., and Athanassiou, C. G. 2004. "Factors Affecting Efficacy of the Diatomaceous Earth Formulation SilicoSec against Adults and Larvae of the Confused Beetle T. confusum du Val (Coleoptera: Tenebrionidae)." Crop Protection 23: 565-73.

[20] Athanassiou, C. G., Kavallieratos, N. G., and Meletsis, C. M. 2007. "Insecticidal Effect of Three Diatomaceous Earth Formulations, Applied alone or in Combination, against Three Stored-product Beetle Species on Wheat and Naize." Journal of Stored Products Research 43: 303-34.

[21] Wakil, W., Riasat, T., and Lord, J. C. 2013. "Effects of Combined Thiamethoxam and Diatomaceous Earth on Mortality and Progeny Production of Four Pakistani Populations of Rhyzopertha dominica (Coleoptera: Bostrichidae) on Wheat, Rice and Maize." Journal of Stored Products Research 52: 28-35.

[22] Rigaux, M., Haubruge, E., and Fields, P. G. 2001. "Mechanisms for Tolerance to Diatomaceous Earth between Strains of Tribolium castaneum." Entomologia Experimentalis et Applicata 101: 33-9.

[23] Vayias, B. J., Athanassiou, C. G., Kavallieratos, N. G., and Buchelos, C. Th. 2006. "Susceptibility of Different European Populations of Tribolium confusum (Coleoptera:
Tenebrionidae) to Five Diatomaceous Earth Formulations." Journal of Economic Entomology 99: 1899-904.

[24] Mewis, I., and Ulrichs, C. 2001. “Action of Amorphous Diatomaceous Earth against Different Stages of the Stored Product Pests Tribolium confusum Jacquelin du Val (Coleoptera: Tenebrionidae), Tenebrio molitor L. (Coleoptera: Tenebrionidae), Sitophilus granarius (L.) (Coleoptera: Curculionidae) and Plodia interpunctella (Hübner) (Lepidoptera: Pyralidae)." Journal of Stored Products Research 37: 153-64.

[25] Fields, P. G., Allen, S., Korunic, Z., Mclaughlin, A., and Stathers, T. 2003. Standardised Testing for Diatomaceous Earth. In: Credland, P. F, Armitage, D. M., Bell, C. H., Cogan, P. M., Highley, E. (Eds), Proceedings of the 8 th International Conference on Stored-Product Protection, CAB International, Wallingford, pp. 779-84.

[26] Abbott, W. S. 1925. "A Method for Computing the Effectiveness of an Insecticide." Journal of Economic Entomology 18: 265-7.

[27] Korunic, Z. 1998. "Diatomaceous Earths, a Group of Natural Insecticides." Journal of Stored Products Research 34: 87-97.

[28] Arthur, F. H., and Throne, J. E. 2003. "Efficacy of Diatomaceous Earth to Control Internal Infestation of Rice Weevil and Maize Weevil (Coleoptera:Curculionidae)." Journal of Economic Entomology 96: 510-8.

[29] Korunic, Z., and Fields, P. G. 2006. "Susceptibility of Three Species of Sitophilus to Diatomaceous Earth.” In: Lorini, I., Bacaltchuk, B., Beckel, H., Deckers, D., Sundfeld, E., dos Santos, J. P., Biagi, J. D., Celaro, J. C., D'A., Faroni, L. R., Bortolini, L. de O. F., Sartori, M. R., Elias, M. C., Guedes, R. N. C., da Fonseca, R. G. \& Scussel, V. M. (Eds) Proceedings of the 9th International Working Conference on Stored-Product Protection, 15-18 October, 2006, Campinas, Sao Paulo, Brazil. Brazilian Post-harvest Association, Campinas, Brazil. pp. 681-6.

[30] Baldassari, N., Prioli, C., Vincenzo, A. M., and Baronio, T. P. 2008. "Insecticidal Efficacy of a Diatomaceous Earth Formulation against a Mixed Age Population of Adults of Rhyzopertha dominica and Tribolium castaneum as Function of Different Temperature and Exposure Time." Bulletin of Insectology 61: 355-60.

[31] Kabir, B. G. J., Lawan, M., and Abdulrahman, H. T. 2012. "The Effects of Raw Diatomaceous Earth (DE) on Mortality and Progeny Development of Rhyzopertha dominica Fab. (Coleoptera: Bostrichidae) and Tribolium castaneum Herbst (Coleoptera: Tenebrionidae) on Three Cereal Grains." Academic Journal of Entomology 5: 16-21.

[32] Vayias, B. J., Athanassiou, C. G., and Buchelos, C. Th. 
2009. "Effectiveness of Spinosad Combined with Diatomaceous Earth against Different European Strains of Tribolium confusum du Val (Coleoptera: Tenebrionidae): Influence of Commodity and Temperature." Journal of Stored Products Research 45: 165-76.

[33] Kavallieratos, N. G., Athanassiou, C. G., Mpakou, F. D., and Mpassoukou, A. E. 2007. "Factors Affecting Laboratory Bioassays with Diatomaceous Earth on Stored Wheat: Effect of Insect Density, Grain Quantity, and Cracked Kernel Containment." Journal of Economic Entomology 100: 1724-31.

[34] Nwaubani, S. I., Opit, G. P., Otitodun, G. O., and Adesida, M. A. 2014. "Efficacy of Two Nigeria-derived Diatomaceous Earths against Sitophilus oryzae (Coleoptera: Curculionidae) and Rhyzopertha dominica (Coleoptera: Bostrichidae) on Wheat." Journal of Stored Products Research 59: 9-16.

[35] Mewis, I., and Reichmuth, C. 1998. Diatomaceous earth against the Coleoptera granary weevil Sitophilus granarius (Curculionidae), the confused flour beetle Tribolium castaneum (Tenebrionidae), the mealworm Tenebriomolitor (Tenebrionidae). In: Proceedings $7^{\text {th }}$ International Working Conference on Stored-Products Protection, Beijing, China, 2, 966-73.

[36] Baldassari, N., Berluti, A., Martini, A., and Baronio, P. 2004. "Analysis of the Sensitivity of Different Stages of Rhyzopertha dominica and Tribolium castaneum to Diatomaceous Earth.” Bulletin of Insectology 57: 95-102.

[37] Stathers, T. E., Dennif, M., and Golob, P. 2004. "The Efficacy and Persistence of Diatomaceous Earths Admixed with Commodity against Four Tropical Stored Product Beetle Pests." Journal of Stored Products Research 40: 113-23.

[38] Timlick, B., and Fields, P. G. 2010. "A Comparison of the Effect of Two Diatomaceous Earth Formulations on Plodia interpunctella (Hübner) and the Effect of Different Commodities on Diatomaceous Earth Efficacy." In: Carvalho, M. O., Fields, P. G., Adler, C. S., Arthur, F. A., Athanassiou, C. G., Campbell, J. F., Fleurat-Lessard, F., Flinn, P. W., Hodges, R. J., Isikber, A. A., Navarro, S., Noyes, R. T., Riudavetes, J., Sinha, K. K., Thorpe, G. R., Timlick, B. H., Trematerra, P., White, N. D. G. (Eds), Proceedings of the 10th International Working Conference on Stored Product Protection, June 27 to 2 July, 2010. Estoril, Portugal. pp. 840-4. 